\title{
Estimating misreporting in condom use and its determinants among sex workers: Evidence from the list randomisation method
}

\author{
Carole Treibich \& Aurélia Lépine
}

\begin{abstract}
Social desirability bias, which is the tendency to under-report socially undesirable health behaviours, significantly distorts information on sensitive behaviours gained from self-reports. We designed a list randomisation method to indirectly elicit condom use among female sex workers and tested it among 651 female sex workers in Senegal, a country where sex workers face high social stigma and where the AIDS epidemic is mainly concentrated among this population. Based on our list randomisation, we found that the condom use rate in the last sexual intercourse with a client was $78 \%$, which is significantly lower than the $97 \%$ obtained when asked directly in the survey. When estimating condom use among the subgroups, we found that female sex workers who are at a higher risk of infection are less likely to use condoms.
\end{abstract}

Key words: list randomisation, condom use, female sex workers, Senegal.

\section{Introduction}

Condom use is the main preventive tool available to limit the spread of sexually transmitted diseases (STIs) and human immunodeficiency virus infection/acquired immune deficiency syndrome (HIV/AIDS). Given that the consistent use of condoms is known as the most costeffective way to prevent HIV transmission (Cohen et al., 2004; Creese et al., 2002), condom 
use is the pillar of any HIV prevention strategy in most countries. The promotion of condom use is often based on multiple interventions such as awareness campaigns and the free provision of condoms. However, the evaluation of the effects of such policies as well as their value for money is difficult to determine due to the impossibility to directly observe sexual behaviours adopted by targeted groups. Researchers and policy makers have no other choice than relying on individuals' declarations. As a matter of fact, in a systematic review looking at the effect of interventions involving condom promotion, Foss et al. (2007) found that most of the evidence published on the effect of such interventions is based on self-reported condom use, despite the inherent bias of such a measure. Indeed, one may wonder whether direct elicitation of condom use would provide an accurate estimate and could be used to measure the impact and monetary value of condom-based interventions. This may be even more of a concern when considering stigmatised groups highly targeted by preventive services, such as female sex workers (FSWs).

Our paper aims to measure misreporting in condom use among FSWs in Senegal, a country particularly interesting for the study of FSWs. First, while HIV prevalence is $0.7 \%$ in the general population, FSWs in Senegal are up to 9 times more likely to be infected, with HIV/AIDS with an HIV/AIDS prevalence of 6.6\% in 2015 (APAPS and IRESSEF, 2015). Second, Senegal is the only African country where prostitution is legal and regulated by a public health policy. In 1969, the Government of Senegal legalised prostitution and introduced a compulsory registration programme for FSWs to monitor the prevalence of STIs, and later on, the spread of the HIV/AIDS epidemic. As a consequence of the close monitoring of this population, registered FSWs are aware of the benefits provided by the use of condoms and receive condoms for free at their monthly routine health visits. Third, Senegal is a Muslim-dominated country where a woman's status is very low. As a result, despite having a legal status, FSWs face very high social stigma. In this context, we anticipate that condom use self-reported in face-to-face surveys is 
likely to be over-reported.

To estimate the amount of over-reporting and the determinants of condom use and of its overreporting, we used list randomisation. The list randomisation method or item count technique provides privacy to respondents and thus limits dishonest answers caused by social desirability bias in face-to-face interviews (Holbrook and Krosnick, 2010). It has been applied to elicit vote preferences (Corstange, 2009; Gonzalez-Ocantos et al., 2012; Holbrook and Krosnick, 2010), illegal migration (McKenzie and Siegel, 2013), the use of micro finance loans (Karlan and Zinman, 2012) as well as opinions on topics such as same sex marriage (Lax et al., 2016) and racism (Blair and Kosuke, 2012; Kuklinski et al., 1997).

However, there are only a few studies that have applied the method in health research (Chong et al., 2013; Jamison et al., 2013; LaBrie and Earleywine, 2000; Walsh and Braithwaite, 2008), and the method has never been used to measure over-reporting in condom use among a low educated stigmatised group. We believe that it is important to assess whether list randomisation could be introduced into national surveys to obtain a less biased estimation of condom use among high-risk groups in low-income countries. In addition to providing a better estimate of condom use, list randomisation allows the identification of subgroups for which condom use rates are lower. We used the parameters from the model by Geoffard and Philipson (1996) to identify the main drivers of condom use. Finally, we compared the proportion of FSWs who openly declared using a condom with their last client with the proportion obtained through the indirect elicitation method to quantify the propensity to over-report condom use among subgroups. By doing so, we are able to test whether registered FSWs, who are by definition more exposed to HIV prevention services, are more likely to over-report condom use than their non-registered counterparts. 
We found that $22 \%$ of FSWs did not use a condom in their last sexual intercourse with a client, which is significantly greater than the $3 \%$ obtained when asked directly. Hence, our results confirm that list randomisation could be a promising indirect method to elicit condom use in low-income countries. When estimating condom use among subgroups, we found that FSWs at a higher risk of HIV are significantly less likely to have used a condom with their last client. The results also show that increasing the knowledge of FSWs regarding HIV and the consequences of STIs as well as increasing the links with health facilities would be useful policies to increase condom use. Finally, we did not find that FSWs receiving more HIV prevention services are more likely to over-report condom use.

\section{Methodology}

\subsection{List randomisation method and underlying hypotheses}

The principle of list randomisation is to allocate respondents randomly into the following two different groups: a "control" and a "treatment" group. Individuals allocated into the "control" group are presented with a number of non-sensitive statements. They are not asked to say whether they agree with each of the statements but only with how many of them they agree with. The same statements are presented to the "treated" group; the difference is that a sensitive statement is added to the series of non-sensitive statements. Assuming that the two groups agree on average with the same number of non-sensitive statements, one can deduce the share of individuals in the "treated" group who agreed with the sensitive item by comparing the average number of agreed statements in each group (see Glynn, 2013; Holbrook and Krosnick, 2010; Kuklinski et al., 1997).

The effectiveness of this methodology is based on the following three assumptions: (i) randomisation of the treatment, (ii) absence of any design effect, and (iii) honest answers. More 
precisely, individuals allocated to each group must be similar to ensure that they agree with the same number of non-sensitive items on average. Second, the addition of the sensitive item must not change the sum of the affirmative answers to the control items. Finally, as pointed out by Kuklinski et al. (1997), the choice of the non-key items needs to be such that individuals are not urged to provide false answers. There are two different types of dishonest answers: those who honestly would answer "yes" to all the non-sensitive items and hence would no longer benefit from any privacy if they agree with the sensitive item (ceiling effects) and those who honestly would answer "no" to all non-sensitive items and hence would no longer benefit from any privacy if they disagree with the sensitive item (floor effects).

\subsection{List randomisation implemented among FSWs in the Dakar region}

In 2015, we interviewed 651 FSWs in the Dakar suburbs, which represents $15 \%$ of the total estimated number of FSWs in the Dakar region (APAPS, 2011-2012). Ethical clearance was obtained from the London School of Hygiene \& Tropical Medicine and from the national ethics committee in Senegal (reference number SEN15/15). Data were captured using electronic devices and all respondents were asked whether they used a condom with their last client. Then, we randomised the allocation of the participants into the "treatment" and "control" groups based on their identifying number to determine their elicited condom use.

In our survey, the "control" group was presented with the following question:

I [the interviewer] will read three statements. I will then ask you how many of these statements you agree with. You should not tell me which specific statement you agree with but the number of statements you agree with. I will give you three marbles, and you have to hold them in your right hand. Keep both of your hands on your back side. For each of the statements, if 
you agree with it, please transfer one marble from your right hand to your left hand behind you. If you do not agree with it, please do not transfer any marble. At the end, I would like to know the total number of statements you agreed with. This number should correspond to the number of marbles you have in your left hand. I will now read the statements.

1. It is safer to bring a client home than going to a hotel.

2. I prefer that the client pays me before intercourse.

3. Monday is the day I have the greatest number of clients.

FSWs from the "treatment" group received an additional marble and were presented the same statements plus the sensitive item that relates to condom use. Note that this sensitive item was presented in the second position in the treatment group list:

4. I used a condom during my last sexual intercourse with a client.

\section{Theoretical framework}

In this section, we present a theoretical framework for the potential mechanisms at play in the decision to engage or not engage in unprotected sex. To do so, we adapted the model by Geoffard and Philipson (1996), which is a two-period model where individuals (in our case FSWs) decide whether to engage or not engage in an unprotected sex act in the period $t$ and face the costs of being infected in the period $t+1$. We added interdependence to the utility functions of FSWs and their clients (Bergstrom, 1999) so that the utility function of (infected) FSWs $u$ depends on their sexual partner's utility level $v$.

As it is commonly done in the literature for the compensating differential for unprotected sex (Arunachalam and Shah, 2012; Gertler and Shah, 2011; Rao et al., 2003), it is assumed that clients bear disutility from using condom. FSWs choose their behaviours to maximise their 
utility given their health state. The health status $h$ of FSWs can take the following two values: susceptible $(h=s)$ or infected with HIV $(h=i)$. FSWs decide to adopt a behaviour $b$ that can also take the following two values: protection against risk $(b=p)$ or exposure to risk $(b=e)$. The utility derived by FSWs $u(h, b)$ is a function of one's health and behaviour.

Ceteris paribus, protective activity $(p)$ and infection $(i)$ are both assumed to be costly as follows:

$$
u(h, e)>u(h, p) \text { and } u(s, b)>u(i, b)
$$

FSWs discount future utility at a discount rate $\delta(h)$, which is a function of their future health state, with $\delta(s)<\delta(i)$.

The transition rate from state $s$ to state $i$, which is conditional on exposure, is denoted as $\lambda=\pi \times P$ where $P$ is the probability that a susceptible FSW matches with an infected client and $\pi$ is the probability that an exposed activity between the FSW and her client will result in a new infection.

The underlying assumptions in the model are as follows:

$$
\begin{gathered}
P[h(t+1)=i \mid(h(t), b)=(s, e)]=\lambda \\
P[h(t+1)=i \mid(h(t), b)=(s, p)]=0 \\
P[h(t+1)=i \mid(h(t), b)=i]=1
\end{gathered}
$$

In other words, (1) the probability of getting infected if exposed for a susceptible FSW is $\lambda$; (2) the probability of being infected under protection is zero and (3) the probability of remaining infected if already infected is one, whichever behaviour is adopted by the FSW.

FSWs engage in safe sex if and only if the cost of protection (the loss of current utility from 
protection) is below the expected future utility loss due to infection.

$$
u(s, e)-u(s, p) \leq \pi \cdot P\left[\frac{u(s)}{\delta(s)}-\frac{u(i)}{\delta(i)}\right]
$$

While in this model, infected FSWs have no reason to engage in safe sex as $u(i, p)<u(i, e)$; thus, we relax this assumption and assume interdependence in the utility functions of FSWs and their clients (Bergstrom, 1999) so that the utility function of (infected) FSWs $u$ depends on their sexual partner's utility level $v$, where

$$
u(i, e)-u(i, p) \leq \pi[u(i, v(s))-u(i, v(i))] \text { with } v(s)>v(i)
$$

\section{Empirical strategy}

Equation (4) shows that condom use estimated by list randomisation was estimated by regressing the number of statements the respondent agreed with $\left(Y_{i}\right)$ on the allocation to the treatment group $\left(T_{i}\right)$. The average condom use rate in the sample using list randomisation is then given by $\beta$ and corresponds to the average difference in the number of statements between the control and the treatment group in the sample. All estimations compute robust standard errors to account for the difference in the variance of error term $\varepsilon_{i}$ between the treatment and control groups.

$$
Y_{i}=\beta T_{i}+\varepsilon_{i}
$$

We use list randomisation to further investigate the characteristics of FSWs who did not use a condom during their last sexual intercourse. ${ }^{1}$ Following Imai (2011), we investigated the

\footnotetext{
${ }^{1}$ The advantage of the list randomisation methodology lies in the possibility of conducting subgroup analysis (see Appendix 1 for a comparison of different techniques eliciting sensitive items).
} 
relation between condom use and respondents' characteristics using a simple linear regression with the following interaction terms:

$$
Y_{i}=\beta T_{i}+\gamma S_{i}+\alpha S_{i} \times T_{i}+\varepsilon_{i}
$$

where $S_{i}$ is a characteristic of individual $i$ that may be correlated with condom use. $\beta$ precisely reports the condom use rate among the subgroup for which $S_{i}=0$, while $\alpha$ is the difference in the condom use rate between the two subgroups $\left(S_{i}=1\right.$ and $\left.S_{i}=0\right)$. The p-value of $\alpha$ indicates if the condom use rate is different between the subgroups.

To improve the statistical power, we added some variables that are assumed to be correlated with the non-sensitive statements:

$$
Y_{i}=\beta T_{i}+\gamma S_{i}+\alpha S_{i} \times T_{i}+X_{i}+\varepsilon_{i}
$$

where $X_{i}$ is a set of sex worker characteristics potentially influencing the answer to the non-sensitive items (i.e., FSW preferences regarding the place where the sex act occurred or the proportion of the last four sexual intercourses for which payment was made after the sex act). $X_{i}$ also includes age, whether the FSW is divorced, whether the FSW lives with or next to her parents, the type of client (regular versus occasional) and whether clients are usually approached in a night club.

\section{Data}

Data were collected from 651 FSWs living in Dakar suburbs in June and July 2015, which represents $15 \%$ of the estimated total FSWs in the Dakar region (APAPS, 2011-2012). Our 
sample contains an equal share of registered and non-registered FSWs. Given that sexual health services are integrated with reproductive health in Senegal, registered FSWs were recruited by the midwife in charge of their medical follow-up. All active registered FSWs from four (Pikine, Rufisque, Mbao and Sebikotane) out of the five STI health centres located in Dakar were contacted to participate in our study. Unregistered FSWs were recruited by NGO staffs and by peer FSWs using snowball sampling. FSWs were asked to come to the health centre and were interviewed at the health facility in private dedicated rooms. Survey participants received a CFAF 3,000 show-up fee that aimed to cover transport cost and the time spent at the health facility.

As part of the questionnaire, information on socio-economic and intrinsic characteristics, preferences (time preferences, risk aversion and altruism) and sex work activity (revenue, type of clients and type of sex acts) was collected from the respondents. Table 1 shows the different parameters from the model with their measurements from the data set and presents descriptive statistics of these variables.

\section{Validation of list randomisation}

\subsection{Verification of the randomisation}

We noted that randomisation ensured balance between the two groups with respect to their observable characteristics (Table A2, Appendix 2). The only significant difference observed was in the type of the sex worker's last client $(\mathrm{p}=0.06)$. However, given that we tested approximately 60 different treatment-control differences in this table, this unique significant difference is no more than what would be expected by chance. This was confirmed by the joint significance tests for a large share of the set of variables presented in Table A2. ${ }^{2}$

\footnotetext{
${ }^{2}$ More precisely, two tests of joint significance were performed and provided similar results. While the first one aimed to maximise the size of the sample considered (645 observations and 32 variables), the second one increased the number of variables included in the model (621 observations and 39 variables).
} 
Table 1: Determinants of condom use.

\begin{tabular}{|c|c|c|c|c|c|}
\hline Parameter & Description & Factors influencing the parameters & $\begin{array}{l}\text { Expected } \\
\text { effect }\end{array}$ & Obs & Mean \\
\hline \multirow[t]{10}{*}{$u(s, e)-u(s, p)$} & \multirow[t]{10}{*}{ Cost of protection } & Revenue loss: & - & & \\
\hline & & Earned more than 12,500 CFAF for the last intercourse & & 643 & 0.499 \\
\hline & & Beauty $(\geq 5$ out of 10$)$ & & 651 & 0.776 \\
\hline & & Condom price: & + & & \\
\hline & & Received free condoms & & 641 & 0.671 \\
\hline & & Reduction in sexual pleasure: & + & & \\
\hline & & $\begin{array}{l}\text { FSWs who declare having no reduction in sexual pleasure } \\
\text { with condoms }\end{array}$ & & 640 & 0.195 \\
\hline & & Violence: & - & & \\
\hline & & The last client negotiated the price & & 605 & 0.534 \\
\hline & & Violence from a client in the past year & & 648 & 0.255 \\
\hline$P$ & $\begin{array}{l}\text { Probability that a } \\
\text { susceptible } \\
\text { individual matched with an } \\
\text { infected one }\end{array}$ & $\begin{array}{l}\text { Client at risk of HIV: } \\
\text { Last client was at risk of HIV }\end{array}$ & + & 593 & 0.73 \\
\hline \multirow[t]{10}{*}{$\pi$} & \multirow{10}{*}{$\begin{array}{l}\text { Probability that an } \\
\text { exposed activity } \\
\text { between them will } \\
\text { result in a } \\
\text { new infection }\end{array}$} & Risk taking: & - & & \\
\hline & & More than 3 clients a week & & 648 & 0.684 \\
\hline & & Subjective risk taking in health domain ( $\geq 8$ out of 10$)$ & & 651 & 0.054 \\
\hline & & Last client was an occasional client & & 645 & 0.440 \\
\hline & & Performed anal sex during last intercourse & & 645 & 0.023 \\
\hline & & HIV and STI knowledge: & + & & \\
\hline & & High HIV knowledge ( $\geq 6$ out of 8 ) & & 651 & 0.796 \\
\hline & & Poor trust towards the efficacy of condoms: & - & & \\
\hline & & Perceived condoms inefficacious to prevent HIV & & 606 & 0.254 \\
\hline & & Agrees with 'One cannot avoid HIV by always using condoms' & & 643 & 0.171 \\
\hline \multirow[t]{10}{*}{$u(i, e)$} & \multirow{10}{*}{$\begin{array}{l}\text { Utility in the case of } \\
\text { infection }\end{array}$} & Social exclusion: & + & & \\
\hline & & Was introduced to the sex business by another SW & & 651 & 0.267 \\
\hline & & Thinks that all girls in the same location use condoms & & 364 & 0.522 \\
\hline & & $\begin{array}{l}\text { Would be ashamed if a neighbour learns about her sex } \\
\text { work activity }\end{array}$ & & 648 & 0.844 \\
\hline & & $\begin{array}{l}\text { Fears that a neighbour who learns about her sex activity } \\
\text { will repeat it to others }\end{array}$ & & 647 & 0.856 \\
\hline & & Medical and opportunity cost: & + & & \\
\hline & & Thinks that will lose more than 14 days of work if has an STI & & 648 & 0.486 \\
\hline & & Expects to pay more than 15,000 CFAF in the case of a genital ulcer & & 634 & 0.364 \\
\hline & & Quality of life if infected: & - & & \\
\hline & & Knows ART & & 647 & 0.504 \\
\hline \multirow[t]{7}{*}{$u(s)$} & \multirow[t]{7}{*}{ Preference for health } & Legal status: & + & & \\
\hline & & Registered with authorities & & 650 & 0.500 \\
\hline & & Demand for prevention: & + & & \\
\hline & & Is affiliated with a health centre & & 648 & 0.731 \\
\hline & & Does her monthly routine visit & & 269 & 0.729 \\
\hline & & Visited a health centre in the last 6 months & & 651 & 0.750 \\
\hline & & Had an HIV screening in the past year & & 651 & 0.806 \\
\hline \multirow[t]{3}{*}{$\delta$} & \multirow[t]{3}{*}{ Discount rate } & Preference for present: & - & & \\
\hline & & Agrees with 'Instead of saving, I prefer to spend my money today' & & 651 & 0.788 \\
\hline & & Alcohol or drug consumption during last intercourse & & 640 & 0.077 \\
\hline \multirow[t]{4}{*}{$u(i, p)<u(i, e)$} & \multirow{4}{*}{$\begin{array}{l}\text { Disutility in using } \\
\text { condoms once } \\
\text { infected }\end{array}$} & HIV and STI status: & - & & \\
\hline & & HIV positive according to medical records (biological test) & & 219 & 0.059 \\
\hline & & Subjective expectations about being HIV positive & & 582 & 0.065 \\
\hline & & Subjective expectations about being STI positive & & 583 & 0.398 \\
\hline \multirow[t]{2}{*}{$u(v(s))$} & \multirow{2}{*}{$\begin{array}{l}\text { Interdependent } \\
\text { utilities }\end{array}$} & Altruism: & + & & \\
\hline & & $\begin{array}{l}\text { Gave more than } 40 \% \text { of the amount received in a } \\
\text { dictator game }\end{array}$ & & 651 & 0.289 \\
\hline
\end{tabular}

Notes: All listed variables are binary variables. 


\subsection{Absence of ceiling, floor and design effects}

We also needed to ensure that the list of non-sensitive items provided enough privacy to respondents in the treated group (hypothesis 2) and that the addition of the sensitive item did not modify the answers regarding the non-sensitive statements (hypothesis 3). In Table A3 (Appendix 2), we estimated the proportion of FSWs in the control group who did not agree with any statement and answered "0" to the item count list question. If this proportion was high, it would encourage respondents in the treated group to report a positive value since answering "0" would reveal that they had unprotected sex. Since the proportion of individuals answering "0" in the control group was less than $3 \%$, we did not face this issue. We also avoided the issue of ceiling effects because the proportion of respondents in the control group who answered "3" to the non-sensitive items was also very low $(9 \%)$. This absence of ceiling and floor effects has been ensured thanks to the negative correlation between items 2 and 3. Some protection for the respondents is therefore built-in to allow them to honestly report their true behaviours towards condom use. Finally, the difference (Row 5) between the proportion of individuals in the treated group (Row 2) and in the control group (Row 4) who agree with at least $j$ statements $(j=1,2,3$, and4) is always positive, which provides evidence of the absence of design effects.

\section{Results}

\subsection{Measuring misreporting in condom use}

Using self-reported information, we found that $97.2 \%$ of FSWs declared to have used a condom with their last client. Table 2 presents the results from the list randomisation exercise. It appears that based on list randomisation, the condom use rate is equal to $79.7 \%$ when considering all female sex workers (Panel A) and $77.7 \%$ versus $97.2 \%$ when self-reported if we consider the sample of FSWs who answered to the self-declared question (Panel B). As a result, the self- 
reported condom use is overestimated by $19.5 \%$ points (95\% CI $[7.5 ; 31.6])$.

The difference between self-reported condom use and the condom use elicited by list randomisation is statistically significant $(p<0.01)$. For the entire sample, i.e., when including the $10.6 \%$ who did not answer the direct question, the elicited condom use rate using list randomisation is 2 percentage points higher. This is an interesting result because it means that respondents who did not answer the self-reported question report slightly higher condom use (see Panel C).

Table 2: Condom use with the last client estimated with the list experiment.

\begin{tabular}{|c|c|c|c|}
\hline & $\begin{array}{c}\text { Average number } \\
\text { of agreed statements }\end{array}$ & \multirow{2}{*}{$\begin{array}{c}\text { Estimated } \\
\text { condom use }\end{array}$} & \multirow[b]{2}{*}{ CI $95 \%$} \\
\hline Control & Treatment & & \\
\hline \multicolumn{4}{|l|}{ Panel A: All female sex workers $(n=651)$} \\
\hline 1.700 & 2.497 & 0.797 & {$[68.52,90.93]$} \\
\hline \multicolumn{4}{|c|}{ Panel B: Restricted to individuals who answered the self-declared question ( $n=582$ ) } \\
\hline 1.685 & 2.462 & 0.777 & {$[65.67,89.75]$} \\
\hline \multicolumn{4}{|c|}{ Panel $\boldsymbol{C}:$ Restricted to individuals who did not answered the self-declared question $(n=69)$} \\
\hline 1.839 & 2.763 & 0.924 & {$[64.10,120.78]$} \\
\hline
\end{tabular}

\subsection{Measuring misreporting in condom use for subgroups}

Table 3 displays the results obtained when performing the subgroup analysis based on the variables presented in Table 1.

Factors affecting the costs of protection We found that having high earnings ${ }^{3}$ is negatively correlated with the likelihood of using a condom $(68.4 \%$ vs. $89.4 \%$, p-value $=0.07)$. Nevertheless, FSWs who received free condoms are not more likely to use condoms than those who have to pay for condoms. In addition to these financial costs, FSWs were asked to compare their sexual pleasure with and without condoms. Those who declared that the use of condom does not decrease their sexual pleasure showed greater condom use, although the difference is

\footnotetext{
${ }^{3}$ More than 12,500 CFAF for the sexual act, which corresponds to the median in our sample
} 
not statistically significant $(94.7 \%$ vs. $76.2 \%$, p-value $=0.17)$. No information regarding the type of violence experienced during the last sexual intercourse was collected. We attempted to overcome this issue (i) by comparing FSWs who suffered from violence by an occasional client in the last twelve months with those who did not and (ii) by looking at whether the last client negotiated the price of intercourse as a proxy for a FSW's low bargaining power. However, we did not find any significant differences in condom use between these subgroups.

Factors affecting the probability that a susceptible FSW matches with an infected client FSWs were asked about their last client characteristics. We found that FSWs are more likely to use a condom with clients perceived to be at high risk of HIV (90.4\% vs. $77.4 \%$ ), though this difference was not statistically significant.

Factors affecting the probability that an exposed activity between a FSW and a client will result in a new infection Having an occasional client reduces the probability of engaging in safe sex even if this difference is not statistically significant. FSWs who have more than three clients per week are significantly less likely to have used a condom $(73.3 \%$ vs. 95.0\%, p-value=0.08). FSWs who declare to be willing to take risks with their health tend to be less likely to use condoms, though the sample size of this subgroup does not enable us to detect a statistically significant difference. FSWs who have a better knowledge regarding HIV transmission modes are more likely to have used a condom with their last client $(85.2 \%$ vs. $58.5 \%$, p-value=0.06). For FSWs who think that condoms will not prevent against HIV infection, they have a lower condom use, but this difference is not statistically significant $(62.0 \%$ vs. $82.9 \%$, p-value $=0.14)$.

Factors affecting the utility in the case of an infection We found that peer effects and social norms play a role in condom use. FSWs who declare that all the girls working in 
their area use condoms are more likely to have used a condom with their last client (98.8\% vs. $63.2 \%, \mathrm{p}$-value $=0.02)$. This is also the case for FSWs who entered sex work thanks to another sex worker $(97.4 \%$ vs. $73.9 \%$, p-value=0.06). Furthermore, we investigated the impact of fear of social stigma on condom use by looking at the following two different variables: those who would be ashamed if a neighbour learns about their sex work activity and those who fear the neighbour would repeat this to others. Both subgroups are more likely to use condoms $(85.2 \%$ vs. $47.2 \%$, p-value $=0.02$ and $84.6 \%$ vs. $42.7 \%$, p-value $=0.02$ respectively).

As expected, perceived high STI consequences are positively associated with the decision to engage in safe sex. On one hand, FSWs who think they will lose more than 14 days of work in the case of an STI are more likely to have used a condom during their last paid intercourse (92.9\% vs. $66.6 \%$, p-value $=0.02)$. Likewise, FSWs who expect to pay more than 15,000 CFAF in medical expenses in the case of a genital ulcer are more likely to have used a condom with their last client $(85.2 \%$ vs. $65.7 \%$, p-value=0.10). FSWs who are aware of the existence of antiretroviral treatment (ART) also displayed lower rate of condom use than FSWs who had never heard about ART, but this difference was not statistically significant (71.5\% vs. 88.9\%, $\mathrm{p}$-value $=0.13)$.

Factors reflecting the preference for health FSWs who visited a health centre in the past six months are more likely to have used a condom $(86.0 \%$ vs. $60.9 \%$, p-value $=0.07)$. However, being a registered FSW and adhering to medical visits is not correlated with condom use.

Factors affecting the discount rate FSWs who declared that they have consumed alcohol or drugs before their last paid sexual intercourse are significantly less likely to have used a condom $(40.7 \%$ vs. $81.4 \%$, p-value $=0.06)$. 
Testing the disutility in using condoms once infected HIV positive FSWs (estimated via biological markers) are less likely to have used a condom than HIV negative FSWs (5.0\% vs $80.0 \%$, p-value $=0.05)$. This negative relationship between HIV status and condom use was somehow confirmed for the entire sample when considering subjective expectations regarding HIV status. Additionally, FSWs who believe that they have another STI than HIV (also estimated via subjective expectations) are significantly less likely to have used a condom with their last client $(57.1 \%$ vs $89.4 \%$, p-value $=0.01)$.

Interdependent utilities We found that altruistic FSWs are more likely to have used a condom $(97.2 \%$ vs. $72.6 \%$, p-value $=0.05)$.

Table A4 (Appendix 3) shows that very similar results were found when introducing the set of covariates aiming at controlling for any sex worker's characteristics, which could influence the answers to the non-sensitive items or when restricting the sample to FSWs who answered the self-declared condom use question. 
Table 3: Condom use by subgroups.

\begin{tabular}{|c|c|c|c|c|c|c|c|c|c|c|c|c|c|}
\hline & & \multicolumn{6}{|c|}{ Self-declared condom use } & \multicolumn{6}{|c|}{ List randomisation $\ddagger$} \\
\hline & & $\begin{array}{l}\text { Obs } \\
(1)\end{array}$ & $\begin{array}{c}\text { Obs if } \\
\text { Yes } \\
(2)\end{array}$ & $\begin{array}{l}\text { Yes } \\
(3)\end{array}$ & $\begin{array}{l}\text { No } \\
(4)\end{array}$ & $\begin{array}{l}\text { Difference } \\
\quad(5)\end{array}$ & $\begin{array}{l}\mathrm{SE} \\
(6)\end{array}$ & $\begin{array}{c}\text { Obs } \\
(7)\end{array}$ & $\begin{array}{c}\text { Obs if } \\
\text { Yes } \\
(8)\end{array}$ & $\begin{array}{l}\text { Yes } \\
(9)\end{array}$ & $\begin{array}{c}\text { No } \\
(10)\end{array}$ & $\begin{array}{l}\text { Difference } \\
\quad(11)\end{array}$ & $\begin{array}{c}\mathrm{SE} \\
(12)\end{array}$ \\
\hline \multirow{9}{*}{ 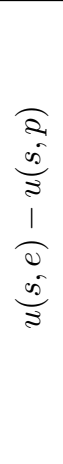 } & Revenue loss: & & & & & & & & & & & & \\
\hline & Earned more than $12,500 \mathrm{CFAF}$ in the last intercourse & 582 & 293 & 0.956 & 0.990 & $-0.034^{\star \star}$ & 0.013 & 643 & 321 & 0.684 & 0.894 & $-0.210^{\star}$ & 0.114 \\
\hline & Beauty ( $\geq 5$ out of 10$)$ & 582 & 461 & 0.972 & 0.975 & -0.003 & 0.016 & 651 & 505 & 0.745 & 0.974 & $-0.230^{\star}$ & 0.131 \\
\hline & Condom price: & 579 & on1 & 007 & 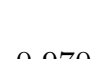 & & & & & & & & \\
\hline & $\begin{array}{l}\text { Recelved free condoms } \\
\text { Reduction in sexual pleasure: }\end{array}$ & 573 & 371 & 0.987 & 0.970 & 0.016 & 0.013 & 641 & 430 & 0.791 & 0.849 & -0.058 & 0.124 \\
\hline & $\begin{array}{l}\text { FSWs who declare having no reduction in sexual pleasure } \\
\text { with condoms }\end{array}$ & 572 & 111 & 0.982 & 0.980 & 0.002 & 0.014 & 640 & 125 & 0.947 & 0.762 & 0.186 & 0.135 \\
\hline & Violence: & & & & & & & & & & & & \\
\hline & The client negotiated the price & 576 & 309 & 0.981 & 0.966 & 0.014 & 0.014 & 605 & 323 & 0.780 & 0.821 & -0.041 & 0.120 \\
\hline & Violence from a client in the past year & 581 & 150 & 0.980 & 0.970 & 0.010 & 0.014 & 648 & 165 & 0.843 & 0.782 & 0.061 & 0.122 \\
\hline 2 & $\begin{array}{l}\text { Client at risk of HIV: } \\
\text { Last client was at risk of HIV }\end{array}$ & 543 & 39 & 0.923 & 0.974 & -0.051 & 0.043 & 593 & 43 & 0.904 & 0.774 & 0.129 & 0.213 \\
\hline \multirow{8}{*}{ E } & Risk taking: & & & & & & & & & & & & \\
\hline & More than 3 clients a week & 581 & 397 & 0.970 & 0.978 & -0.008 & 0.014 & 648 & 443 & 0.733 & 0.950 & -0.217 & 0.122 \\
\hline & Subjective risk taking in health domain ( $\geq 8$ out of 10$)$ & 582 & 33 & 0.939 & 0.974 & -0.035 & 0.042 & 651 & 35 & 0.500 & 0.812 & -0.312 & 0.230 \\
\hline & $\begin{array}{l}\text { Last client was an occasional client } \\
\text { HIV and STI knowledge: }\end{array}$ & 582 & 266 & 0.981 & 0.965 & 0.016 & 0.013 & 645 & 284 & 0.711 & 0.860 & -0.148 & 0.115 \\
\hline & High HIV knowledge $(\geq 6$ out of 8$)$ & 582 & 460 & 0.980 & 0.943 & $0.038^{\star}$ & 0.022 & 651 & 518 & 0.852 & 0.585 & $0.266^{\star}$ & 0.144 \\
\hline & Poor trust towards the efficacy of & & & & & & & & & & & & \\
\hline & Perceived condoms inefficacious to prevent $\mathrm{HIV}^{\dagger}$ & 543 & 125 & 0.992 & 0.967 & $0.025^{\star \star}$ & 0.012 & 606 & 154 & 0.620 & 0.829 & -0.209 & 0.142 \\
\hline & Agrees with 'One cannot avoid HIV by always using condoms' & 576 & 101 & 0.960 & 0.979 & -0.019 & 0.021 & 640 & 110 & 0.618 & 0.830 & -0.212 & 0.150 \\
\hline \multirow{9}{*}{ 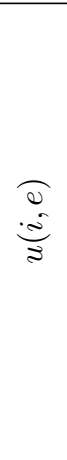 } & Social exclusion: & & & & & & & & & & & & \\
\hline & Was introduced to the sex business by another sex worker & 582 & 165 & 0.982 & 0.969 & 0.013 & 0.013 & 651 & 174 & 0.974 & 0.739 & $0.234^{\star}$ & 0.122 \\
\hline & Thinks that all girls in the same location use condoms & 322 & 163 & 1.000 & 0.975 & $0.025^{\star \star}$ & 0.012 & 364 & 190 & 0.988 & 0.632 & $0.356^{\star \star}$ & 0.151 \\
\hline & Would be ashamed if a neighbour learns about her sex work activity & 579 & 485 & 0.975 & 0.957 & 0.018 & 0.022 & 648 & 547 & 0.852 & 0.472 & $0.380^{\star \star}$ & 0.160 \\
\hline & $\begin{array}{l}\text { Fears that a neighbour who learns about her sex activity will } \\
\text { repeat it to others }\end{array}$ & 578 & 493 & 0.976 & 0.953 & 0.023 & 0.024 & 647 & 554 & 0.846 & 0.427 & $0.419^{\star \star}$ & 0.181 \\
\hline & Medical and opportunity cost: & & & & & & & & & & & & \\
\hline & Thinks that will lose more than 14 days of work if has an STI & 581 & 283 & 0.968 & 0.977 & -0.008 & 0.014 & 648 & 315 & 0.929 & 0.666 & $0.263^{\star \star}$ & 0.114 \\
\hline & $\begin{array}{l}\text { Expects to pay more than } 15,000 \text { CFAF in the case of a genital ulcer } \\
\text { Quality of life if infected: }\end{array}$ & 568 & 368 & 0.965 & 0.985 & -0.020 & 0.013 & 634 & 403 & 0.852 & 0.657 & 0.195 & 0.119 \\
\hline & Know ART & 581 & 290 & 0.983 & 0.962 & 0.021 & 0.014 & 647 & 326 & 0.715 & 0.889 & -0.173 & 0.114 \\
\hline
\end{tabular}


Table 3: Condom use by subgroups (continued).

\begin{tabular}{|c|c|c|c|c|c|c|c|c|c|c|c|c|c|c|}
\hline & & & \multicolumn{6}{|c|}{ Self-declared condom use } & \multicolumn{6}{|c|}{ List randomisation $\ddagger$} \\
\hline & & & $\begin{array}{l}\text { Obs } \\
(1)\end{array}$ & $\begin{array}{c}\text { Obs if } \\
Y e s \\
(2)\end{array}$ & Yes & No & $\begin{array}{l}\text { Difference } \\
\quad(5)\end{array}$ & $\begin{array}{l}\text { SE } \\
(6)\end{array}$ & $\begin{array}{l}\text { Obs } \\
(7)\end{array}$ & $\begin{array}{c}\text { Obs if } \\
\text { Yes } \\
(8)\end{array}$ & $\begin{array}{l}\text { Yes } \\
(9)\end{array}$ & No & $\begin{array}{l}\text { Difference } \\
\quad(11)\end{array}$ & $\begin{array}{l}\text { SE } \\
(12)\end{array}$ \\
\hline \multirow{7}{*}{$\overbrace{\curvearrowright}^{\infty}$} & & Legal status: & & & & & & & & & & & & \\
\hline & & Registered with authorities & 582 & 271 & 0.985 & 0.961 & $0.024^{\star}$ & 0.013 & 650 & 325 & 0.848 & 0.749 & 0.100 & 0.115 \\
\hline & & Demand for prevention: & & & & & & & & & & & & \\
\hline & & Is affiliated with health centre & 580 & 416 & 0.978 & 0.957 & 0.021 & 0.017 & 648 & 474 & 0.843 & 0.680 & 0.163 & 0.133 \\
\hline & & Does her monthly routine visit & 224 & 156 & 0.993 & 1.000 & -0.006 & 0.006 & 269 & 196 & 0.841 & 0.711 & 0.130 & 0.190 \\
\hline & & Visited a health centre in the last 6 months & 582 & 427 & 0.981 & 0.948 & $0.033^{\star}$ & 0.019 & 651 & 488 & 0.860 & 0.609 & $0.251^{\star}$ & 0.137 \\
\hline & & Had an HIV screening in the past year & 582 & 464 & 0.983 & 0.932 & $0.051^{\star \star}$ & 0.024 & 651 & 525 & 0.803 & 0.774 & 0.029 & 0.153 \\
\hline \multirow{3}{*}{\multicolumn{2}{|c|}{$\infty$}} & Preference for present: & & & & & & & & & & & & \\
\hline & & Agrees with 'Instead of saving I prefer spending my money today' & 582 & 472 & 0.972 & 0.973 & -0.001 & 0.017 & 651 & 513 & 0.791 & 0.809 & -0.018 & 0.138 \\
\hline & & Alcohol or drug consumption during last intercourse & 579 & 41 & 1.000 & 0.970 & $0.030^{\star \star \star}$ & 0.007 & 640 & 49 & 0.407 & 0.814 & $-0.407^{\star}$ & 0.218 \\
\hline \multirow{4}{*}{ 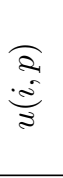 } & & HIV and STI status: & & & & & & & & & & & & \\
\hline & $\stackrel{0}{\approx=}$ & HIV positive according to medical records (biological test) & 185 & 10 & 1.000 & 0.994 & 0.006 & 0.006 & 219 & 13 & 0.050 & 0.800 & $-0.750^{\star}$ & 0.384 \\
\hline & ב & Subjective expectations about being HIV positive ${ }^{\diamond}$ & 521 & 32 & 0.969 & 0.973 & -0.005 & 0.032 & 582 & 38 & 0.421 & 0.787 & -0.366 & 0.278 \\
\hline & V & Subjective expectations about being STI positive ${ }^{\diamond}$ & 521 & 207 & 0.966 & 0.978 & -0.012 & 0.015 & 583 & 232 & 0.571 & 0.894 & $-0.323^{\star \star \star}$ & 0.124 \\
\hline$\frac{\underset{a}{\frac{0}{2}}}{\frac{\pi}{3}}$ & & $\begin{array}{l}\text { Altruism: } \\
\text { Gave more than } 40 \% \text { of the amount received in the dictator game }\end{array}$ & 582 & 170 & 0.976 & 0.971 & 0.006 & 0.014 & 651 & 188 & 0.972 & 0.726 & $0.245^{\star \star}$ & 0.125 \\
\hline
\end{tabular}

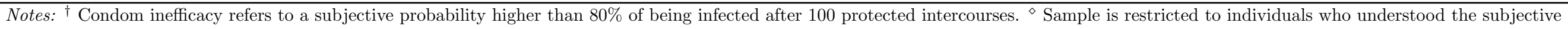

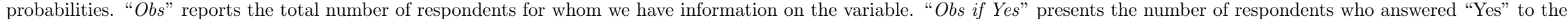
related question. Columns (3) and (9) [Columns (4) and (10), respectively] display the proportion of FSWs who answered "Yes" ["No"] and who used a condom in their last sexual act.

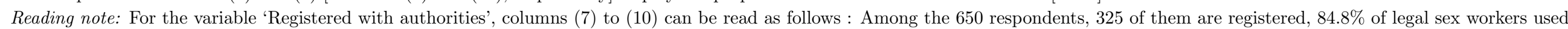
a condom with their last client, and $74.9 \%$ of illegal sex workers used a condom with their last client.

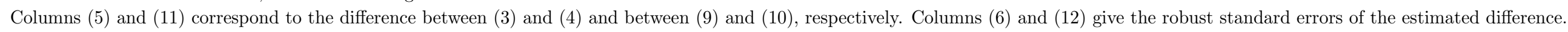

$\ddagger$ List randomisation - estimation: equation (5): $Y_{i}=\beta T_{i}+\gamma S_{i}+\alpha S_{i} \times T_{i}+\varepsilon_{i}$. Reported levels of significance are ${ }^{\star} \mathrm{p}<0.1,{ }^{\star \star} \mathrm{p}<0.05$ and ${ }^{\star \star \star} \mathrm{p}<0.01$. 


\subsection{The role of prevention on condom use over-reporting}

An important concern is whether high-risk populations who are more exposed to intensive HIV prevention services tend to over-report more condom use. To measure the role of prevention on condom use over-reporting, we perform the following procedure. First, we computed the proportion of FSWs who declared using a condom with their last client depending on their registration status, assuming that registered FSWs are more exposed to HIV prevention than non-registered FSWs. Then, we estimated condom use for those groups using the list randomisation results presented in Table 3. Finally, we computed the difference in condom use obtained with the two methods as well as its associated standard error. Table 4 reports the propensity to over-report condom use depending on HIV prevention exposure. Overall, there is no evidence that FSWs receiving intensive HIV prevention services are more likely to over-report condom use. Conversely, we found that FSWs who have not visited a health centre in the last six months tend to be more likely to over-report their condom use when compared to FSWs who recently attended a health centre, though this result is not statistically significant.

Table 4: Social desirability bias.

\begin{tabular}{|c|c|c|c|c|c|c|}
\hline & \multirow{3}{*}{ Obs } & \multirow{3}{*}{$\begin{array}{c}\text { Obs if } \\
Y e s\end{array}$} & \multicolumn{2}{|c|}{$\begin{array}{l}\text { Over-reporting } \\
\text { estimation }\end{array}$} & \multirow{3}{*}{$\begin{array}{l}\text { Difference } \\
\quad(3)\end{array}$} & \multirow{3}{*}{$\begin{array}{l}\mathrm{SE} \\
(4)\end{array}$} \\
\hline & & & Yes & No & & \\
\hline & & & $(1)$ & $(2)$ & & \\
\hline \multicolumn{7}{|l|}{ Legal status } \\
\hline Registered with authorities & 650 & 325 & 0.137 & 0.213 & -0.076 & 0.122 \\
\hline Is affiliated with a health centre & 648 & 474 & 0.135 & 0.277 & -0.142 & 0.129 \\
\hline \multicolumn{7}{|c|}{ Access to HIV prevention and linked to the health system } \\
\hline Visited a health centre in the past 6 months & 651 & 488 & 0.121 & 0.339 & -0.218 & 0.144 \\
\hline Visited a health centre less than a month ago & 651 & 368 & 0.122 & 0.246 & -0.124 & 0.112 \\
\hline Does her monthly visits & 269 & 196 & 0.152 & 0.289 & -0.136 & 0.185 \\
\hline Received free condoms & 641 & 430 & 0.196 & 0.122 & 0.074 & 0.125 \\
\hline Had an HIV screening in the past year & 651 & 525 & 0.179 & 0.158 & 0.021 & 0.161 \\
\hline \multicolumn{7}{|c|}{$\begin{array}{l}\text { Notes: (1) and (2) correspond to the difference in condom use with the direct and indirect measures for the control } \\
\text { group and the treated group, respectively. (3) is the difference between }(1) \text { and }(2) \text {. (4) is the standard error of }(3) \\
\text { and is equal to the square root of the sum of the squared standard errors of }(1) \text { and }(2) \text { (not reported in this table). } \\
\text { The p-value indicates whether the difference is significantly different from zero and has been computed as follows: } \\
\text { p-value }=2 \times \text { normal(-abs }((3) /(4)) \text {. None of the differences are statistically significant at the } 10 \% \text { level or lower. } \\
\text { "Obs" reports the total number of respondents for whom we have information, i.e., } 650 \text { respondents. "Obs if Yes" } \\
\text { presents the number of respondents who answered "Yes" to the question, i.e., } 325 \text { respondents are registered. }\end{array}$} \\
\hline
\end{tabular}




\section{Discussion}

Using list randomisation, we found that FSWs in Dakar over-report condom use by 19.5 points. The misreporting in condom use is higher than previously reported in the literature. Previous studies concluded that condom use was overestimated by 11 points among college students in the United States (LaBrie and Earleywine, 2000) and by 14 points among young men in Uganda, but condom use was neither overestimated among young women (Jamison et al., 2013) nor among teenagers in Colombia (Chong et al., 2013). The high misreporting in our study is likely to be explained by the characteristics of the targeted population; given that sex work is morally condemned by the Senegalese society, FSWs fear to be looked down upon when disclosing socially unacceptable behaviours in a face-to-face survey. Hence, by guaranteeing anonymity, the list randomisation method seems particularly suited to this population. Nonetheless, we acknowledge that condom use may still be overestimated. While list randomisation guarantees privacy in response to survey participants, it cannot help with participants who do not want to reveal their true behaviours. For example, we found that among the respondents who did not answer the self-declared condom use question, only $8 \%$ did not use condoms with their last client according to list randomisation, which may indicate that condom use is still overestimated in this sub-sample (see Table 2, Panel C).

We empirically tested the role of the main parameters from Geoffard and Philipson (1996)'s model. We found that one of the main reasons for not using condom comes from the existence of a premium for unprotected sex (Gertler et al., 2005; Rao et al., 2003). By showing that more expensive sex acts were more likely to be unprotected, our results confirm the important role of clients in the AIDS epidemic. Policies that would aim to reduce the strong preference of clients for unprotected sex could be effective in limiting HIV transmission. While a main barrier to 
condom use is the fact that condom use is under the client's control (Wojcicki and Malala, 2001), our data show that only $7 \%$ of the 1,629 protected sexual intercourses contained in our data set were protected using a female condom. This suggests that the low bargaining power of FSWs may not be the main reason for not using condoms and justifies why FSWs with a lower bargaining power or FSWs exposed to physical violence from a client are not less likely to use condoms in our data set.

Our results provide some evidence on the role of factors affecting the utility in the case of infection upon condom use. First, we showed that FSWs who fear social stigma are more likely to use condoms. This indicates that while stigma reduction policies will certainly reduce social exclusion of FSWs, the absence of social sanctions could lead to greater risk-taking. Second, we found that condom use is significantly higher for FSWs who anticipate that infection will lead to important direct and indirect costs and a lower quality of life. For example, we found that women who have heard about ART are less likely to use condoms. There is some evidence in the literature that ART roll out is associated with greater risk taking (Geoffard and Méchoulan, 2004; Gray et al., 2003). However, the negative relationship between ART knowledge and condom use could also come from the fact that FSWs on ART have a lower incentive to use protection, ceteris paribus. To test this, we excluded FSWs who believed that they were infected with HIV from our sample, which reinforced the negative relationship between ART knowledge and condom use. FSWs who knew about ART had a lower condom use by 25 points and this difference was statistically significant at $5 \%$.

The model by Geoffard and Philipson (1996) predicts that once infected, FSWs should stop using condoms because the benefits provided from protection is nil; this was confirmed empirically. This result is particularly alarming because it shows that the riskiest sexual intercourses 
are more likely to be unprotected compared with safer ones. In fact, we estimate that among the 4,225 sexual intercourses that occur weekly in our sample, $8 \%$ involved HIV positive FSWs. This is because HIV positive FSWs have on average 7 weekly clients (compared to 6.5 for HIV negative ones). Among those 329 sexual intercourses that are particularly at risk of infection, only 16 were protected according to the list randomisation results. However, the increased likelihood of adopting risky sexual behaviours once infected can be mitigated if we assume interdependent utilities. When testing this empirically, we find that altruistic HIV positive FSWs have a condom use rate that is 85 points greater than non-altruistic HIV positive FSWs, although the difference was not statistically significant given the small sample ( $\mathrm{p}$-value $=0.12$ ).

While our results are novel and in line with economic theory predictions, our study has several limitations. First, the small size of our sample prevents us from detecting moderate differences in condom use for a few subgroups. In addition to the issue of low statistical power, the small sample size also leads to higher uncertainty in the estimated proportion of condom use for several subgroups. For instance, while we estimate that the condom use by HIV positive FSWs (according to biological markers) is only 5\%; this result may be attributable to the small HIV prevalence in our sample. In the treated group of HIV positive FSWs, the average number of true statements was 2.2 , while it was 1.7 in the total sample, leading to an underestimation of condom use for this subgroup. When considering the number of true statements in the total sample, list randomisation concludes that condom use is 20 points lower for HIV positive FSWs. Despite the impossibility to investigate the causal effect of HIV status on condom use, our findings confirm that FSWs are an important vector of HIV transmission in Senegal. An important limitation however is that while we assume that clients bear disutility from using condoms, the data did not allow us to investigate the role of client preferences on condom use. 
Future research on the use of the list randomisation method to elicit sexual behaviours could be conducted along three axes. First, additional methodological research that would provide guidance regarding the optimal design of list randomisation is required. While the number and choices of non-key items should not affect the results in theory, there is some empirical evidence that the choice of non-key items does matter (Droitcour et al., 1991). Unlike previous papers using list randomisation to elicit condom use (Chong et al., 2013; Jamison et al., 2013; LaBrie and Earleywine, 2000; Walsh and Braithwaite, 2008) and building on the agreement in the recent literature that it is better to select non-key items that relate to the topic of interest (see Imai et al., 2015; Karlan and Zinman, 2012; Wolter and Laier, 2014), our non-key items are related to sex work activity. Second, we showed that results obtained from list randomisation are to some extent imprecise, and, given the implementation challenges when performing a list randomisation, the method is often applied to small samples. When the length of the survey allows it, a double list randomisation where each group serves once as the control group and once as the treated group can increase precision (Glynn, 2013). Finally, future research on condom use measurements should aim to test the validity of the results obtained with list randomisation. This could be performed by asking condom use question to clients in addition to FSWs since clients are less likely to over-report condom use (Wilson et al., 1989) or to compare the results obtained with the list randomisation to results obtained with another indirect elicitation method.

\section{Conclusion}

We implemented list randomisation on FSWs to test if condom use was over-reported. Our results are consistent with the fact that self-reported condom use leads to a large overestimation of condom use, which has direct implications when this measure is used to assess the impact 
and the value for money of condom-based interventions. When analysing the determinants of condom use, we provide some alarming evidence on the fact that sexual intercourses most at risk of infection are more likely to be unprotected than safer ones. We also highlight some important factors that affect the decision to engage in unprotected sex. While many of those factors have something to do with a FSW's personality and social norms, and hence are hardly changeable, our results also suggest that a mix of policies that consist of both educating FSWs and clients on the benefits of protected sex and reducing the costs associated with protected sex could be effective to increase condom use. 


\section{References}

APAPS. Etude pour l'estimation du nombre de ts et de hsh dans la région de dakar. Technical report, commanditée par la DLSI, le CNLS et FHI, 2011-2012.

APAPS and IRESSEF. Enquête nationale de surveillance combinée des ist et du vih/sida (ensc). Technical report, 2015.

Raj Arunachalam and Manisha Shah. Compensated for life: Sex work and disease risk. Journal of Human Resources, 48(2):345-69, 2012.

T.C. Bergstrom. System of benevolent utility functions. Journal of Economic Theory, 1(1): 71-100, 1999.

Graeme Blair and Imai Kosuke. Statistical analysis of list experiments. Political Analysis, 20 (1):47-77, 2012.

Alberto Chong, Marco Gonzalez-Navarro, Dean Karlan, and Martin Valvidia. Do information technologies improve teenagers sexual education? evidence from a randomized evaluation in colombia. NBER Working Papers 18776, 2013.

D.A. Cohen, S.-Y. Wu, and T.A. Farley. Comparing the cost-effectiveness of hiv prevention interventions. JAIDS Journal of Acquired Immune Deficiency Syndromes, 37(3):1404-1414, 2004.

Daniel Corstange. Sensitive questions, truthful answers? modeling the list experiment with listit. Political Analysis, 17(1):45-63, 2009.

A. Creese, K. Floyd, A. Alban, and L. Guinness. Cost-effectiveness of hiv/aids interventions in africa: a systematic review of the evidence. The Lancet, 359(9318):1635-1642, 2002. 
Judith Droitcour, Rachel A. Caspar, Michael L. Hubbard, Teresa L. Parsley, Wendy Visscher, and Trena M. Ezzati. The item-count technique as a method of indirect questioning: A review of its development and a case study application. Measurement Errors in Surveys, pages 185-210, 1991.

AM. M. Foss, M. Hossain, P.T. Vickerman, and C.H. Watts. A systematic review of published evidence on intervention impact on condom use in sub-saharan africa and asia. Sexually Transmitted Infections, 83(7):510-16, 2007.

Pierre-Yves Geoffard and Stéphane Méchoulan. Comportements sexuels risqus et incitations: Limpact des nouveaux traitements sur la prvention du vih. Revue Economique, 55(5):883-99, 2004 .

Pierre-Yves Geoffard and Tomas Philipson. Rational epidemics and their public control. International Economic Review, 37(3):603-24, 1996.

Paul J. Gertler and Manisha Shah. Sex work and infection: What's law enforcement got to do with it? Journal of Law and Economics, 54(4):811-40, 2011.

Paul J. Gertler, Manisha Shah, and Stephano Bertozzi. Risky business: The market for unprotected commercial sex. Journal of Political Economy, 113(3):518-550, 2005.

Adam N. Glynn. What can we learn with statistical truth serum? design and analysis of the list experiment. Public Opinion Quarterly, 77(S1):159-72, 2013.

Ezequiel Gonzalez-Ocantos, Chad Kiewiet de Jonge, Carlos Meléndez, Javier Osorio, and David W. Nickerson. Vote buying and social desirability bias: Experimental evidence from nicaragua. American Journal of Political Science, 56(1):202-17, 2012.

R.H. Gray, X. Li, M.J. Wawer, S.J. Gange, D. Serwadda, N.K. Sewankambo, R. Moore, F. Wabwire-Mangen, T. Lutalo, T.C. Quinn, and Rakai Project Group. Stochastic simu- 
lation of the impact of antiretroviral therapy and hiv vaccines on hiv transmission; rakai, uganda. AIDS, 17(13):1941-51, 2003.

Allyson L. Holbrook and Jon A. Krosnick. Social desirability bias in voter turnout reports: Tests using the item count technique. Public Opinion Quarterly, 74(1):37-67, 2010.

Kosuke Imai. Multivariate regression analysis for the item count technique. Journal of the American Statistical Association, 106(494):407-416, 2011.

Kosuke Imai, Bethany Park, and Kenneth F. Greene. Using the predicted responses from list experiments as explanatory variables in regression models. Political Analysis, 23(2):180-96, 2015.

Julian C. Jamison, Dean Karlan, and Pia Raffler. Mixed-method evaluation of a passive mhealth sexual information texting service in uganda. Information Technologies \& International Development, 9(3):1-28, 2013.

Dean S. Karlan and Jonathan Zinman. List randomization for sensitive behavior: An application for measuring use of loan proceeds. Journal of Development Economics, 98(1):71-75, 2012.

J.H. Kuklinski, M.D. Cobb, and M. Gilens. Racial attitudes and the new south. The Journal of Politics, 59(2):323-49, 1997.

J. W. LaBrie and M. Earleywine. Sexual risk behaviors and alcohol: Higher base rates revealed using the unmatched-count technique. Journal of Sex Research, 37(4):321-26, 2000.

Jeffrey R. Lax, Justin H. Phillips, and Alissa F. Stollwerk. Are survey respondents lying about their support for same-sex marriage? lessons from a recent list experiment. Public Opinion Quarterly, 80(2):510-33, 2016. 
David McKenzie and Melissa Siegel. Eliciting illegal migration rates through list randomization. Migration Studies, 1(3):253-57, 2013.

V. Rao, I. Gupta, M. Lokshin, and S. Jana. Sex workers and the cost of safe sex: The compensating differential for condom use among calcutta prostitutes. Journal of Development Economics, 71(2):585-603, 2003.

J.A. Walsh and J. Braithwaite. Self-reported alcohol consumption and sexual behavior in males and females: Using unmatched-count technique to examine reporting practices of socially sensitive subjects in a sample of university students. Journal of Alcohol and Drug Education, 52(2):49-72, 2008.

D. Wilson, P. Chiroro, S. Lavelle, and C. Mutero. Sex worker, client sex behaviour and condom use in harare, zimbabwe. AIDS Care, 1(3):269-80, 1989.

Janet Maia Wojcicki and Josephine Malala. Condom use, power and hiv/aids risk: Sexworkers bargain for survival in hillbrow/joubert park/berea, johannesburg. Social Science and Medicine, 53(1):99-121, 2001.

Felix Wolter and Bastian Laier. The effectiveness of the item count technique in eliciting valid answers to sensitive questions. an evaluation in the context of self-reported delinquency. Survey Research Methods, 8(3):153-68, 2014. 


\section{Appendices}

\section{Appendix 1 Techniques eliciting sensitive items}

Table A1 presents several techniques aiming at ensuring confidentiality and summarizes the strengths and weaknesses of each of them. We believe that given the low-literacy level of FSWs and the policy relevance of performing a sub-group analysis, the list randomisation methodology was the most appropriate method to estimate misreporting in condom use.

Table A1: Strengths and weaknesses of measurement techniques eliciting sensitive items.

\begin{tabular}{|c|c|c|c|}
\hline Methodology & Description & Strengths & Weaknesses \\
\hline $\begin{array}{l}\text { List } \\
\text { randomisation }\end{array}$ & $\begin{array}{l}\text { Respondents are allocated randomly to two } \\
\text { different groups. They are asked on how many of } j \\
\text { non-sensitive items (plus one sensitive item) they } \\
\text { agree on if they belong to the control group (to the } \\
\text { treated group). }\end{array}$ & $\begin{array}{l}\text { - Enumerators do not know with } \\
\text { which items respondents agree on } \\
\text { - Can be implemented in low- } \\
\text { literacy settings } \\
\text { - Allows sub-group analysis }\end{array}$ & $\begin{array}{l}\text { - Imprecise results, hence } \\
\text { requires large sample } \\
\text { - Success depends on the } \\
\text { design and on enumerators } \\
\text { understanding of the method }\end{array}$ \\
\hline Ballot box & $\begin{array}{l}\text { Respondents fill in a form with no identifier which } \\
\text { is then put in a sealed envelope }\end{array}$ & $\begin{array}{l}\text { - Enumerators never ask directly } \\
\text { the sensitive question }\end{array}$ & $\begin{array}{l}\text { - Population under study } \\
\text { must be literate } \\
\text { - Impossibility to perform } \\
\text { sub-group analyses }\end{array}$ \\
\hline $\begin{array}{l}\text { Randomised } \\
\text { response } \\
\text { technique }\end{array}$ & $\begin{array}{l}\text { Respondents use a participant-controlled } \\
\text { randomised device not seen by the interviewer. } \\
\text { Depending on the outcome of the device, the } \\
\text { respondent provides an automatic response or a } \\
\text { truthful response }\end{array}$ & $\begin{array}{l}\text { - Enumerators do not know if } \\
\text { the response is true or automatic }\end{array}$ & $\begin{array}{l}\text { - Population under study } \\
\text { must be literate }\end{array}$ \\
\hline Diaries & $\begin{array}{l}\text { Respondents complete digital diaries on a daily } \\
\text { basis about their daily activities including } \\
\text { potentially the sensitive behaviour }\end{array}$ & $\begin{array}{l}\text { - No recall bias issue } \\
\text { - No face-to-face interview } \\
\text { - Insights into event level } \\
\text { factors impacting the adoption } \\
\text { of the sensitive behaviour }\end{array}$ & $\begin{array}{l}\text { - Population under study } \\
\text { must be literate } \\
\text { - Need a safe place to hide } \\
\text { the diary }\end{array}$ \\
\hline $\begin{array}{l}\text { Qualitative } \\
\text { approach }\end{array}$ & $\begin{array}{l}\text { Enumerators spend time with respondents and } \\
\text { report the respondent's admission of adopting the } \\
\text { sensitive behaviour }\end{array}$ & $\begin{array}{l}\text { - Trust building and time } \\
\text { invested by validators should } \\
\text { reduce the under-reporting of } \\
\text { the sensitive behaviour }\end{array}$ & $\begin{array}{l}\text { - Need to recruit } \\
\text { enumerators who can } \\
\text { approach respondents and } \\
\text { spend time with them } \\
\text { without modifying their } \\
\text { habits }\end{array}$ \\
\hline $\begin{array}{l}\text { Nominative } \\
\text { technique }\end{array}$ & $\begin{array}{l}\text { Respondents are asked to report (i) how many of } \\
\text { their close friends adopt the sensitive behaviour of } \\
\text { interest, (ii) how many of other close friends of } \\
\text { each reported individual who adopt the sensitive } \\
\text { behaviour also know about it. This allows } \\
\text { calculation of weights that correct for multiple } \\
\text { reports of one particular individual. }\end{array}$ & $\begin{array}{l}\text { - Enumerators do not know } \\
\text { about whom the incriminated } \\
\text { information is being provided }\end{array}$ & $\begin{array}{l}\text { - Response accuracy for } \\
\text { the second question is } \\
\text { questionable }\end{array}$ \\
\hline
\end{tabular}




\section{Appendix 2 Verification of the list randomisation hypothesis}

Table A2: Tests of randomisation.

\begin{tabular}{|c|c|c|c|c|}
\hline Variables & $\begin{array}{c}\text { Observations } \\
651\end{array}$ & $\begin{array}{c}\text { Control } \\
323\end{array}$ & $\begin{array}{c}\text { Treated } \\
328\end{array}$ & p-value \\
\hline \multicolumn{5}{|l|}{ Socio-demographic characteristics } \\
\hline Age (in years) * & 651 & 35.58 & 36.16 & 0.421 \\
\hline Has the legal age (above 21 ) & 651 & 96.28 & 97.56 & 0.346 \\
\hline Is divorced $\star$ & 651 & 67.80 & 70.73 & 0.419 \\
\hline Never married * & 651 & 25.70 & 23.17 & 0.454 \\
\hline Has at least one child & 651 & 86.38 & 89.63 & 0.201 \\
\hline Number of children * & 651 & 2.53 & 2.50 & 0.813 \\
\hline Age of first child & 573 & 19.16 & 19.12 & 0.905 \\
\hline Menopausal & 642 & 21.70 & 25.62 & 0.244 \\
\hline Use contraceptive methods & 495 & 86.96 & 86.78 & 0.953 \\
\hline Use condoms as contraceptive method & 495 & 52.57 & 49.17 & 0.451 \\
\hline Went to koranic school & 646 & 8.46 & 7.65 & 0.703 \\
\hline Highest level of education achieved * & 650 & 1.07 & 1.01 & 0.446 \\
\hline Has a regular partner * & 651 & 46.13 & 41.16 & 0.202 \\
\hline Lives alone & 647 & 16.56 & 16.21 & 0.903 \\
\hline Household size * & 651 & 6.26 & 6.24 & 0.957 \\
\hline Number of moving out in the past year * & 651 & 0.235 & 0.332 & 0.392 \\
\hline Dead mother ${ }^{\star}$ & 651 & 30.96 & 36.28 & 0.151 \\
\hline Dead father & 649 & 65.84 & 65.14 & 0.851 \\
\hline Mother lives in Dakar * & 651 & 52.01 & 49.70 & 0.555 \\
\hline Father lives in Dakar * & 651 & 19.81 & 22.56 & 0.392 \\
\hline HH monthly expenditures * & 651 & 358,017 & 349,909 & 0.757 \\
\hline Monthly sex revenues (CFAF) & 649 & 134,498 & 132,299 & 0.821 \\
\hline Perceived wealth $(1 \text { to } 10)^{*}$ & 651 & 3.82 & 3.90 & 0.675 \\
\hline HH members received transfers in the past year & 649 & 27.73 & 25.00 & 0.431 \\
\hline $\mathrm{HH}$ members sent transfers in the past year & 647 & 38.87 & 38.11 & 0.843 \\
\hline Altruism for talibe $(\mathrm{CFAF})^{\star}$ & 651 & 266 & 278 & 0.537 \\
\hline Altruism for sex worker (CFAF) * & 651 & 140 & 131 & 0.601 \\
\hline Risk aversion in general (1 to 10$)$ * & 651 & 6.31 & 6.19 & 0.579 \\
\hline Risk aversion in sex (1 to 10$) \star$ & 651 & 7.76 & 7.64 & 0.567 \\
\hline Preferences for future (1 to 10$){ }^{*}$ & 651 & 6.69 & 6.88 & 0.457 \\
\hline Trust in others & 648 & 82.19 & 81.10 & 0.721 \\
\hline Life satisfaction $(1$ to 4$){ }^{*}$ & 650 & 2.20 & 2.25 & 0.470 \\
\hline Beauty (1 to 10$)^{*}$ & 651 & 5.81 & 5.80 & 0.930 \\
\hline Health status (0 to 100$)$ * & 651 & 73.92 & 73.21 & 0.677 \\
\hline Feelings of helplessness ( 1 to 4$){ }^{\star}$ & 651 & 3.23 & 3.18 & 0.529 \\
\hline Fear of discrimination due to HIV & 614 & 67.43 & 71.61 & 0.261 \\
\hline Fear of discrimination due to sex work & 633 & 74.52 & 73.67 & 0.807 \\
\hline Family knows about sex work & 641 & 28.39 & 26.85 & 0.664 \\
\hline Feel respected $(1 \text { to } 10)^{\star}$ & 651 & 7.63 & 7.37 & 0.148 \\
\hline HIV knowledge (score $0-8)$ * & 651 & 6.32 & 6.45 & 0.186 \\
\hline
\end{tabular}


Table A2: Tests of randomisation (continued).

\begin{tabular}{|c|c|c|c|c|}
\hline Variables & $\begin{array}{c}\text { Observations } \\
651\end{array}$ & $\begin{array}{c}\text { Control } \\
323\end{array}$ & $\begin{array}{c}\text { Treated } \\
328\end{array}$ & p-value \\
\hline \multicolumn{5}{|l|}{ Sex work activity } \\
\hline Work mostly in bars or brothels * & 651 & 23.84 & 26.83 & 0.381 \\
\hline Work mostly at home * & 651 & 28.48 & 29.57 & 0.760 \\
\hline Experience in sex work ${ }^{\ddagger}$ (in years) & 650 & 7.64 & 8.51 & 0.147 \\
\hline Age at first sexual intercourse * & 650 & 17.24 & 17.28 & 0.891 \\
\hline Age at first paid sexual intercourse * & 650 & 27.94 & 27.61 & 0.594 \\
\hline Has only occasional clients $\diamond$ & 645 & 11.32 & 14.98 & 0.170 \\
\hline Has only regular clients $\diamond$ & 645 & 33.02 & 32.42 & 0.871 \\
\hline Last client was occasional ${ }^{\diamond}$ & 645 & 40.37 & 47.68 & 0.062 \\
\hline Declared use of condom with last client & 582 & 97.60 & 96.90 & 0.603 \\
\hline Number of clients within a week $\diamond$ & 648 & 6.49 & 6.56 & 0.893 \\
\hline \multicolumn{5}{|c|}{ Link with the authorities and the health system } \\
\hline Legal sex worker $(\mathrm{LSW})$ * & 650 & 47.68 & 52.29 & 0.240 \\
\hline LSW since more than one year & 650 & 37.46 & 38.53 & 0.779 \\
\hline Thinks sex work is legal & 610 & 60.30 & 64.22 & 0.315 \\
\hline Police violence in the last 12 months * & 651 & 6.81 & 7.93 & 0.587 \\
\hline LSW who go to her monthly visits & 269 & 72.87 & 72.86 & 0.998 \\
\hline Has received free condoms $\diamond$ & 641 & 65.41 & 68.73 & 0.372 \\
\hline Is affiliated with a STD centre ${ }^{\diamond}$ & 648 & 72.36 & 74.01 & 0.637 \\
\hline Came to a STD centre in the last month * & 651 & 56.97 & 56.10 & 0.824 \\
\hline Had an HIV screeng in the past year * & 651 & 81.11 & 80.18 & 0.764 \\
\hline HIV positive according to medical records & 219 & 4.90 & 6.84 & 0.548 \\
\hline Has got STI symptoms in the last month ${ }^{\diamond}$ & 646 & 20.67 & 23.55 & 0.383 \\
\hline
\end{tabular}

Test of joint significance (when considering the variables indicated by ${ }^{\star}$ ):

$\mathrm{F}(32,612)=0.63$, $\mathrm{p}$-value $=0.947$

Test of joint significance (when considering the variables indicated by ${ }^{\star}$ and ${ }^{\diamond}$ ): $\mathrm{F}(39,581)=0.76, \mathrm{p}$-value $=0.855$

Notes: $\ddagger$ Experience in sex work $=$ age - age at first paid sexual intercourse. 
Table A3: Checking floor, ceiling and design effects.

\begin{tabular}{|c|c|c|c|c|c|c|c|c|}
\hline \multirow{2}{*}{$\begin{array}{l}\text { Estimated } \\
\text { Proportions }\end{array}$} & \multirow[b]{2}{*}{ Source } & \multirow[b]{2}{*}{ Obs. } & \multicolumn{5}{|c|}{ Number of reported items } & \multirow[b]{2}{*}{ Sum } \\
\hline & & & 0 & 1 & 2 & 3 & 4 & \\
\hline Row 1 & Treatment list & 328 & 0.006 & 0.079 & 0.409 & 0.424 & 0.082 & 1.000 \\
\hline Row 2 & Proportion at least & & 1 & 0.994 & 0.915 & 0.506 & 0.082 & - \\
\hline Row 3 & Control list & 323 & 0.028 & 0.334 & 0.548 & 0.090 & 0 & 1.000 \\
\hline Row 4 & Proportion at least & & 1 & 0.972 & 0.638 & 0.090 & 0 & - \\
\hline Row 5 & Row2 - Row 4 & & 0 & 0.022 & 0.0277 & 0.416 & 0.082 & 0.796 \\
\hline
\end{tabular}

\section{Appendix 3 Robustness checks}


Table A4: Robustness checks - Condom use by subgroups.

\begin{tabular}{|c|c|c|c|c|c|c|c|c|c|c|c|c|c|}
\hline & & \multicolumn{6}{|c|}{ List randomisation (Panel B) $\ddagger$} & \multicolumn{6}{|c|}{ List randomisation $($ Panel A) $\mp$} \\
\hline & & $\begin{array}{l}\text { Obs } \\
(1)\end{array}$ & $\begin{array}{l}\text { Obs if } \\
\text { Yes } \\
(2)\end{array}$ & Yes & No & $\begin{array}{l}\text { Difference } \\
\quad(5)\end{array}$ & $\begin{array}{l}\text { SE } \\
(6)\end{array}$ & $\begin{array}{l}\text { Obs } \\
(7)\end{array}$ & $\begin{array}{l}\text { Obs if } \\
\text { Yes } \\
(8)\end{array}$ & Yes & No & $\begin{array}{l}\text { Difference } \\
\quad(11)\end{array}$ & $\begin{array}{c}\text { SE } \\
(12)\end{array}$ \\
\hline \multirow{7}{*}{ 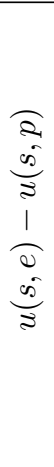 } & Revenue loss: & & & & & & & & & & & & \\
\hline & Earned more than 12,500 CFAF for the last intercourse & 582 & 293 & 0.668 & 0.890 & $-0.221^{\star}$ & 0.122 & 642 & 321 & 0.635 & 0.952 & $-0.317^{\star \star \star}$ & 0.110 \\
\hline & Beauty $(\geq 5$ out of 10$)$ & 582 & 461 & 0.726 & 0.970 & $-0.244^{\star}$ & 0.147 & 644 & 500 & 0.737 & 0.977 & $-0.240^{\star}$ & 0.129 \\
\hline & Received free condoms & 573 & 371 & 0.785 & 0.801 & -0.016 & 0.131 & 634 & 424 & 0.776 & 0.850 & -0.074 & 0.119 \\
\hline & $\begin{array}{l}\text { FSWs who declare having no reduction in sexual pleasure } \\
\text { with condoms } \\
\text { Violence: }\end{array}$ & 572 & 111 & 0.981 & 0.729 & $0.251^{\star}$ & 0.149 & 633 & 124 & 0.919 & 0.759 & 0.160 & 0.132 \\
\hline & The client negotiated the price & 576 & 309 & 0.768 & 0.815 & -0.047 & 0.123 & 605 & 323 & 0.804 & 0.795 & 0.009 & 0.116 \\
\hline & Violence from a client in the past year & 581 & 150 & 0.844 & 0.751 & 0.093 & 0.127 & 643 & 164 & 0.851 & 0.765 & 0.086 & 0.117 \\
\hline A & $\begin{array}{l}\text { Client at risk of HIV: } \\
\text { Last client was at risk of HIV }\end{array}$ & 543 & 39 & 0.888 & 0.747 & 0.140 & 0.233 & 592 & 43 & 0.931 & 0.777 & 0.154 & 0.230 \\
\hline \multirow{8}{*}{$k$} & Risk taking: & & & & & & & & & & & & \\
\hline & More than 3 clients a week & 581 & 397 & 0.712 & 0.945 & $-0.234^{\star}$ & 0.131 & 642 & 440 & 0.733 & 0.944 & $-0.212^{\star}$ & 0.117 \\
\hline & Subjective risk taking in health domain ( $\geq 8$ out of 10 ) & 582 & 33 & 0.474 & 0.792 & -0.318 & 0.243 & 644 & 35 & 0.583 & 0.801 & -0.218 & 0.210 \\
\hline & $\begin{array}{l}\text { Last client was an occasional client } \\
\text { HIV and STI knowledge: }\end{array}$ & 582 & 266 & 0.717 & 0.838 & -0.121 & 0.123 & 644 & 284 & 0.717 & 0.849 & -0.131 & 0.112 \\
\hline & High HIV knowledge $(\geq 6$ out of 8$)$ & 582 & 460 & 0.831 & 0.574 & $0.257^{\star}$ & 0.151 & 644 & 512 & 0.841 & 0.602 & $0.239^{\star}$ & 0.134 \\
\hline & Poor trust towards the efficacy of condoms: & & & & & & & & & & & & \\
\hline & Perceived condoms inefficacious to prevent $\mathrm{HIV}^{\dagger}$ & 543 & 125 & 0.495 & 0.829 & $-0.334^{\star \star}$ & 0.162 & 599 & 152 & 0.611 & 0.819 & -0.208 & 0.137 \\
\hline & Agrees with 'One cannot avoid HIV by always using condoms' & 576 & 101 & 0.591 & 0.811 & -0.220 & 0.152 & 633 & 110 & 0.617 & 0.823 & -0.206 & 0.146 \\
\hline \multirow{9}{*}{ 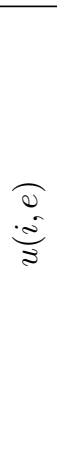 } & Social exclusion: & & & & & & & & & & & & \\
\hline & Was introduced to the sex business by another SW & 582 & 165 & 0.981 & 0.701 & $0.279^{\star \star}$ & 0.129 & 644 & 172 & 0.959 & 0.735 & $0.224^{\star}$ & 0.119 \\
\hline & Thinks that all girls in the same location use condoms & 322 & 163 & 0.899 & 0.655 & 0.244 & 0.160 & 360 & 189 & 0.955 & 0.673 & $0.282^{\star}$ & 0.148 \\
\hline & Would be ashamed if a neighbour learns about her sex work activity & 579 & 485 & 0.836 & 0.440 & $0.396^{\star \star}$ & 0.171 & 641 & 540 & 0.848 & 0.468 & $0.380^{\star \star}$ & 0.153 \\
\hline & $\begin{array}{l}\text { Fears that a neighbour who learns about her sex activity will } \\
\text { repeat it to others }\end{array}$ & 578 & 493 & 0.825 & 0.410 & $0.415^{\star \star}$ & 0.194 & 640 & 547 & 0.837 & 0.469 & $0.367^{\star \star}$ & 0.174 \\
\hline & Medical and opportunity cost: & & & & & & & & & & & & \\
\hline & Thinks that will lose more than 14 days of work if has an STI & 581 & 283 & 0.911 & 0.639 & $0.272^{\star \star}$ & 0.122 & 641 & 313 & 0.937 & 0.649 & $0.288^{\star \star \star}$ & 0.110 \\
\hline & $\begin{array}{l}\text { Expects to pay more than } 15,000 \text { CFAF in the case of a genital ulcer } \\
\text { Quality of life if infected: }\end{array}$ & 568 & 368 & 0.841 & 0.612 & $0.229^{\star}$ & 0.129 & 627 & 401 & 0.840 & 0.656 & 0.184 & 0.117 \\
\hline & Know ART & 581 & 290 & 0.686 & 0.870 & -0.184 & 0.123 & 640 & 325 & 0.702 & 0.890 & $-0.188^{\star}$ & 0.110 \\
\hline
\end{tabular}


Table A4: Robustness checks - Condom use by subgroups (continued).

\begin{tabular}{|c|c|c|c|c|c|c|c|c|c|c|c|c|c|c|}
\hline & & & \multicolumn{6}{|c|}{ List randomisation (Panel B) $\ddagger$} & \multicolumn{6}{|c|}{ List randomisation $($ Panel $\mathrm{A}) \mp$} \\
\hline & & & \multicolumn{3}{|c|}{ Obs if } & & \multirow{3}{*}{$\begin{array}{c}\text { Difference } \\
\quad(5)\end{array}$} & \multirow{3}{*}{$\begin{array}{l}\text { SE } \\
(6)\end{array}$} & \multicolumn{4}{|c|}{ Obs if } & \multirow{3}{*}{$\begin{array}{l}\text { Difference } \\
\quad(11)\end{array}$} & \multirow{3}{*}{$\begin{array}{c}\mathrm{SE} \\
(12)\end{array}$} \\
\hline & & & Obs & Yes & Yes & No & & & Obs & $Y e s$ & Yes & No & & \\
\hline & & & $(1)$ & $(2)$ & $(3)$ & $(4)$ & & & $(7)$ & $((8)$ & $(9)$ & $(10)$ & & \\
\hline \multirow{7}{*}{$\overbrace{\overrightarrow{3}}^{\infty}$} & & Legal status: & & & & & & & & & & & & \\
\hline & & Registered with authorities & 582 & 271 & 0.846 & 0.723 & 0.123 & 0.122 & 643 & 322 & 0.821 & 0.762 & 0.059 & 0.111 \\
\hline & & Demand for prevention: & & & & & & & & & & & & \\
\hline & & Is affiliated with a health centre & 580 & 416 & 0.830 & 0.649 & 0.181 & 0.141 & 641 & 470 & 0.834 & 0.686 & 0.148 & 0.128 \\
\hline & & Does her monthly routine visit & 224 & 156 & 0.871 & 0.705 & 0.166 & 0.204 & 266 & 193 & 0.826 & 0.693 & 0.133 & 0.186 \\
\hline & & Visited a health centre in the last 6 months & 582 & 427 & 0.845 & 0.592 & $0.253^{\star}$ & 0.143 & 644 & 484 & 0.842 & 0.638 & 0.204 & 0.129 \\
\hline & & Had an HIV screening in the past year & 582 & 464 & 0.786 & 0.745 & 0.041 & 0.161 & 644 & 521 & 0.794 & 0.776 & 0.019 & 0.147 \\
\hline \multirow{3}{*}{\multicolumn{2}{|c|}{$\infty$}} & Preference for present: & & & & & & & & & & & & \\
\hline & & Agrees with 'Instead of saving I prefer to spend my money today' & 582 & 472 & 0.760 & 0.822 & -0.062 & 0.159 & 644 & 507 & 0.789 & 0.782 & 0.007 & 0.134 \\
\hline & & Alcohol or drug consumption during last intercourse & 579 & 41 & 0.400 & 0.804 & -0.405 & 0.248 & 639 & 49 & 0.348 & 0.822 & $-0.474^{\star \star}$ & 0.208 \\
\hline \multirow{4}{*}{ 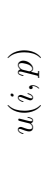 } & & HIV and STI status: & & & & & & & & & & & & \\
\hline & $\therefore$ & HIV positive according to medical records (biological test) & 185 & 10 & 0.167 & 0.808 & -0.641 & 0.404 & 216 & 13 & 0.221 & 0.765 & $-0.543^{\star}$ & 0.287 \\
\hline & $\sqrt{3}$ & Subjective expectations about being HIV positive $\diamond$ & 521 & 32 & 0.375 & 0.761 & -0.386 & 0.291 & 575 & 38 & 0.479 & 0.769 & -0.290 & 0.267 \\
\hline & $\vee$ & Subjective expectations about being STI positive ${ }^{\diamond}$ & 521 & 207 & 0.525 & 0.877 & $-0.352^{\star \star \star}$ & 0.132 & 576 & 231 & 0.621 & 0.843 & $-0.221^{\star}$ & 0.122 \\
\hline$\frac{\substack{\frac{3}{3} \\
\frac{3}{3}}}{2}$ & & $\begin{array}{l}\text { Altruism: } \\
\text { Gave more than } 40 \% \text { of the amount received in the dictator game }\end{array}$ & 582 & 170 & 0.927 & 0.715 & 0.213 & 0.133 & 644 & 187 & 0.954 & 0.723 & $0.231^{\star}$ & 0.124 \\
\hline
\end{tabular}

Notes: Panel B corresponds to the restricted sample i.e. to respondents who answered to the self-declared condom use question (582 out of 650 FSWs) and Panel A to the full sample.

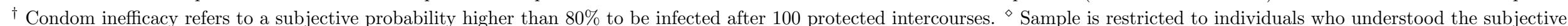
probabilities. "Obs" reports the total number of respondents for whom we have information on the variable. "Obs if Yes" presents the number of respondents who answered "Yes" to the related question. Columns (3) and (9) [Columns (4) and (10)] display the proportion of FSWs who answered "Yes" ["No"] and who used a condom in their last sexual act.

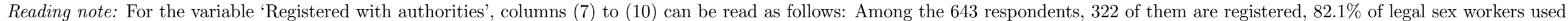
a condom with their last client, $76.2 \%$ of illegal sex workers did so.

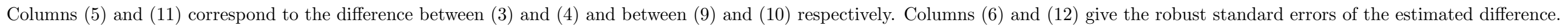

$\ddagger$ Equation (5): $Y_{i}=\beta T_{i}+\gamma S_{i}+\alpha S_{i} \times T_{i}+\varepsilon_{i}$.

₹ Equation (6): $Y_{i}=\beta T_{i}+\gamma S_{i}+\alpha S_{i} \times T_{i}+X_{i}+\varepsilon_{i} . X_{i}$ include age, whether the FSW is divorced, whether the FSW lives with or next to her parents,

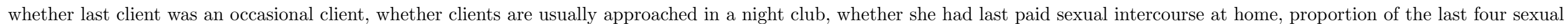

intercourses for which payment was made after the sex act.

Reported levels of significance are ${ }^{\star} \mathrm{p}<0.1,{ }^{\star \star} \mathrm{p}<0.05$ and ${ }^{\star \star \star} \mathrm{p}<0.01$. 